\title{
$>$ W. G. Sebald: reino dos mortos e espetáculo midiático \\ $>$ W. G. Sebald: realm of the dead and mediatic spectacle
}

\section{Kelvin Falcão Klein}

Professor Doutor, Centro de Letras e Artes, Programa de Pós-Graduação em História, Universidade Federal do Estado do Rio de Janeiro (UNIRIO). E-mail: kelvin.klein@gmail.com. ORCID: 0000-0002-8997-1174.

\section{Resumo}

O objetivo do artigo é investigar as possíveis relações entre a reflexão teórica de Friedrich Kittler (especialmente em seu livro Grammophon Film Typewriter) e a produção literária de W. G. Sebald (especialmente seu último romance, Austerlitz). Minha hipótese é que Sebald mescla dois registros diagnosticados por Kittler: acessa o "reino dos mortos" (codificado com base nos resíduos materiais das fotografias) a partir tanto do paradigma técnico-midiático inaugurado com o gramofone, o filme e a máquina de escrever quanto do paradigma anterior, literário e alucinatório, apreendido por Kittler nas obras de Poe e Balzac, entre outros.

Palavras-chave: W. G. Sebald. Friedrich Kittler. Mídia. Fotografia. Romance.

\begin{abstract}
The aim of the article is to investigate possible contacts between Friedrich Kittler's theoretical reflection (especially in his book Grammophon Film Typewriter) and the literary production of W. G. Sebald (especially his latest novel, Austerlitz). My hypothesis is that Sebald merges two fields diagnosed by Kittler: he accesses the "realm of the dead" (coded from the material residues of photographs) from both the technical-media paradigm inaugurated with the "gramophone, film and typewriter" and from the previous paradigm, literary and hallucinatory, apprehended by Kittler in the works of Poe and Balzac, among others.
\end{abstract}

Keywords: W. G. Sebald. Friedrich Kittler. Media. Photography. Novel. 
Em 1986, Friedrich Kittler publica seu livro Grammophon Fïlm Typewriter, dedicado à arqueologia do gramofone, do filme e da máquina de escrever, ou seja, dos três dispositivos que reconfiguraram o campo das mídias e das comunicações nas décadas finais do século XIX. Ele havia publicado, até o momento, outros três livros. Dedicou o primeiro, em 1977, ao escritor Conrad Ferdinand Meyer (1825-1898) e às situações de comunicação presentes em sua obra (Der Traum und die Rede. Eine Analyse der Kommunikationssituation Conrad Ferdinand Meyers). Dois anos depois, em 1979, publicou em conjunto com Gerhard Kaiser um volume sobre Goethe e Gottfried Keller (Dichtung als Sozialisationsspiel. Studien zu Goethe und Gottfried Keller). Por fim, em 1986, lançou um de seus livros mais representativos, dedicado aos sistemas de comunicação e discurso no século XIX (Aufschreibesysteme 180o/190o), que, de certa forma, preparou o terreno para o livro do ano seguinte. Parte da argumentação de Kittler em Grammophon Fỉm Typewriter defende a hipótese de que toda inovação técnica gera uma equivalente transformação da paisagem imaginativa e dos artefatos artísticos daí decorrentes. Até certo ponto, o argumento central pode ser resumido na ideia de que toda manifestação artística corresponde a uma inscrição peculiar visando o registro - por vezes inadvertido - da atmosfera tecnológica de sua época. Para Kittler, "cada teoria tem o seu a priori histórico"1, ou seja, todo discurso está historicamente situado dentro de um jogo constante de aproximação e repulsão diante do panorama técnico.

Antes da transformação técnica implementada pelos três dispositivos do título de Kittler, a escrita literária buscava dar conta da articulação dos diferentes sentidos - especialmente dos dados óticos e acústicos. Mesmo com a intervenção da imprensa - com a passagem da caligrafia, que marca a autoria, para a impressão impessoal, que marca a difusão técnica do literário -, a escrita literária opera a partir de uma deliberada confusão entre literatura e natureza, entre experiência de leitura e experiência espontânea do mundo. Citando Novalis, Schlegel e Goethe, Kittler monta um panorama que visa dar conta da literatura (especialmente nas primeiras décadas do século XIX) como a

${ }^{1}$ Friedrich Kittler, Gramofone, filme, typewriter, 2019, p. 40. 
sustentação de um paradigma alucinatório: em Os sofrimentos do jovem Werther, por exemplo, as cartas manuscritas são simultaneamente requisitadas e tornadas impossíveis, não apenas porque é a mão de Goethe que cria essa multiplicidade de identidades, mas também porque o romance como tal transformado em artefato técnico pela intervenção da prensa - inscreve em sua trama a instabilidade caligráfica que os tipos móveis tornam obsoleta.

Kittler cita, ainda, E. T. A. Hoffman e sua ideia de que a descrição poética deve promover um choque no leitor, mesclando sensação e alucinação, evocando cores, sombras e luzes. A eletricidade dá um fim nisso, pois "lembranças e sonhos, mortos e fantasmas se tornam tecnicamente reprodutíveis", fazendo da "força da alucinação" algo desnecessário tanto nos escritores quanto nos leitores: "nosso reino dos mortos deixou os livros nos quais habitou por tanto tempo", escreve Kittler, "o nosso reino dos mortos transformou-se num espetáculo midiático" ${ }^{2}$. Como qualquer categoria do discurso, o reino dos mortos varia conforme se transforma a técnica e o aparato imaginativo de um dado contexto histórico - os fantasmas se manifestam de formas diversas tendo à disposição a fotografia, o fonógrafo, o código Morse, o cinema ou as ondas do rádio. Não se trata apenas do comportamento dos fantasmas (ou seja, do estabelecimento de descrições possíveis visando a projeção de um estado metafísico da experiência), mas também, e sobretudo, da estreita relação existente entre técnica e imaginação: a variação tecnológica dos dispositivos ao longo do tempo redunda sempre em variação dos regimes discursivos disponíveis para a descrição das fronteiras entre vida e morte.

Em 2000, revendo e ampliando o escopo das análises de Kittler, Stefan Andriopoulos publica Possuídos: crimes hipnóticos, ficção corporativa e a invenção do cinema, dando início a uma exploração do campo de historicização da possessão. Andriopoulos afirma que, "ao atribuir vida a seres espectrais invisíveis, capazes de exercer sua ação em múltiplos lugares”, o discurso jurídico do fim do século XIX “partilhou um terreno comum” com “os textos literários do

\footnotetext{
${ }^{2}$ Ibidem, p. 33 .
} 
fantástico e a prática cultural do ocultismo, ambos contemporâneos"3. Em 2013, com Aparições espectrais: o idealismo alemão, o romance gótico e a mídia óptica, Andriopoulos aprimora suas teses, desloca seu campo de atuação e mostra como o espírito dos filósofos está ligado aos fantasmas das sessões espíritas e dos espetáculos de variedades: “a Fenomenologia do espírito funciona como uma retroprojeção textual, por assim dizer, pois evoca uma sucessão de imagens espectrais e imita o uso da lanterna mágica nas projeções fantasmagóricas, sem citar o nome do instrumento óptico"4. Andriopoulos define sua abordagem como pós-kittleriana, expandindo sua espectrologia em direção a uma discussão das obras de Jacques Derrida, Jonathan Crary, Lorraine Daston e Peter Galison (buscando estabelecer um terreno teórico que o permita revisitar as obras de Kant, Hegel e Schopenhauer).

Ao falar da transformação do reino dos mortos em espetáculo midiático, Kittler evoca alguns precursores - alguns textos do século XIX que preparam o terreno para a reconfiguração midiática -, dentre os quais eu gostaria de destacar o caso de Balzac e sua relação com Félix Nadar, pioneiro da fotografia. Kittler resgata o medo do escritor francês diante da tecnologia de captura de imagens fotográficas, qualificando o daguerreótipo como um truque maligno responsável pelo enfraquecimento das múltiplas camadas superpostas infinitamente finas que formam a fisicalidade e a corporalidade de todo sujeito. “Álbuns de fotografia criam um reino dos mortos infinitamente mais preciso do que seria dado ao empreendimento literário concorrente balzaquiano da Comédie humaine”, escreve Kittler, e continua: “As mídias, em contraposição às artes, não se limitam justamente a terem que trabalhar com a grade do

\footnotetext{
${ }^{3}$ Stefan Andriopoulos, Possuídos: crimes hipnóticos, ficção corporativa e a invenção do cinema, 2014, p. 68. Andriopoulos enfatiza sua filiação com Kittler e também seu afastamento: "Embora se esforce para imitar a riqueza arquivística que marca a arquelogia das mídias, tal como praticada por Kittler e outros, este estudo pressupõe uma interação da emergência de uma nova tecnologia com os discursos culturais circundantes" (p. 25).

${ }^{4}$ Idem, Aparições espectrais: o idealismo alemão, o romance gótico e a nídia óptica, 2014, p. 71. Sobre Kittler, Andriopoulos ainda comenta: "De acordo com Kittler, a rede discursiva de 1800 caracterizava-se por um monopólio do livro, no qual os leitores alucinavam de um modo que se transformaria em realidade tecnológica no meio de comunicação cinematográfico em torno de 1900. Essa justaposição de duas configurações midiáticas centenárias ignora o uso cultural da lanterna mágica na mídia visual da fantasmagoria. Ao mesmo tempo, confia numa teleologia em que o surgimento do cinema torna-se a meta ou, na terminologia de Kittler, a 'implementação' de sonhos discursivos anteriores" (p. 173).
} 
simbólico. Elas reconstroem corpos, isto é, não apenas no sistema de palavras ou cores ou intervalos de tons" ${ }^{5}$. De certa forma, Balzac percebe que a nova técnica de registro do arquivo familiar, social e comunitário ameaça a legibilidade de seu próprio projeto na Comédia humana - algo traduzido na pitoresca percepção de Balzac de que a fotografia descascaria as camadas invisíveis e espectrais dos sujeitos a ela expostos.

Anos depois, em 2002, quando publica Optische Medien, Kittler retorna ao caso de Balzac, aprofundando seu comentário. Kittler relembra que Balzac, "que pretendia criar suas figuras fictícias como daguerreótipos", disse a Nadar, "o primeiro e mais famoso fotógrafo de retratos da França, que ele mesmo tinha pavor de ser fotografado"; Balzac, "com suas tendências místicas”, só conseguia imaginar o ser humano como um ser "que consiste em muitas camadas ópticas”, como uma cebola, das quais "cada fotografia retira e arquiva a camada superior, descascando-a, portanto, da pessoa fotografada”, até causar o desaparecimento da pessoa retratada, "transformando-a em fantasma sem corpo". Kittler aproxima Balzac de Edgar Allan Poe, que "generalizou essa fantasmagoria”, em The Oval Portrait: o pintor de Poe retrata sua amada sem perceber que, "na medida em que o retrato a óleo adquire a cor da carne humana”, a amada se torna cada vez mais pálida; quando o pintor de Poe completa seu quadro fictício, a amante morre - mais uma vez, completa Kittler, "resta à análise midiática enfatizar como as fantasmagorias ou (como diria Jürgen Link) os símbolos coletivos históricos se apoiam em tecnologias”. Os medos de Balzac ou de Poe descrevem o fato evidenciado pela teoria de Rudolf Arnheim, segundo a qual surgiu com a fotografia uma técnica de arquivamento que, pela primeira vez, "reproduziu o objeto representado em sua materialidade inconcebível”6.

Como a obra de W. G. Sebald se comporta diante desse cenário? Em outra ocasião, busquei mostrar o aproveitamento hermenêutico de uma metáfora crítica desenvolvida por Georges Didi-Huberman quando em contato com a obra de Sebald, ou seja, a ideia de um olho da história, que ganharia uma modulação particular em um livro como Guerra aérea e literatura -

${ }^{5}$ Friedrich Kittler, Op. Cit., 2019, p. 34.

${ }^{6}$ Idem, Mídias ópticas, 2016, p. 194-195. 
especialmente no que diz respeito à articulação com a obra de Bertolt Brecht e a conceituação da noção de "povo"7. Além disso, ao deslocar o foco em direção à questão da pós-memória, busquei analisar parte da obra de Sebald a partir de três momentos: em primeiro lugar, o uso ecfrástico que faz Sebald de Albrecht Altdorfer em seu poema Nach der Natur (1988); em segundo lugar, a apropriação do Roland Barthes de A câmara clara feita em entrevistas; e, finalmente, a leitura detida de uma das seções de Vertigem (1990), na qual a figura de Franz Kafka é aproximada à de Jean Paul. A hipótese defendida é de que a fronteira que rege as passagens entre palavra e imagem diz respeito também ao contato entre memória e experiência, desembocando em uma reflexão acerca da constituição do sujeito histórico e seu acesso ao discurso e à arte. ${ }^{8}$ Por fim, uma investigação prévia me levou a pensar a relação da obra de Sebald com o caráter histórico dos modos de atenção na virada do século XIX para o XX, seguindo a argumentação de Jonathan Crary em Suspensões da percepção. Esse movimento inicial serviu de base para a exploração crítica da noção de atenção flutuante, a partir de Sigmund Freud, e das categorias de sociedade do espetáculo e deriva, a partir de Guy Debord, visando estabelecer a pertinência dessas questões no interior de uma leitura da obra de Sebald, especialmente seu romance Os anéis de Saturno (1995). ${ }^{9}$

Minha hipótese agora é que Sebald, em suas ficções, deliberadamente mescla os dois registros, acessando o reino dos mortos a partir tanto do paradigma técnico-midiático inaugurado com o gramofone, o filme e a máquina de escrever quanto do paradigma anterior, alucinatório, apreendido por Kittler nas obras de Poe e Balzac, entre outros. Em certo sentido, ao escrever sua obra ficcional a partir de fins da década de 1980 (até 2001, ano de lançamento de Austerlitz e de sua morte), Sebald acompanha Andriopoulos e pode ser definido como um pós-kittleriano (por mais que Kittler tenha falecido em 2011, dez anos depois de Sebald, tendo ampliado consideravelmente sua obra após os livros da década de 1980, que estou privilegiando em minha análise). Esse depois de Kittler, no entanto, pode ser percebido na obra de Sebald como um esforço

\footnotetext{
${ }^{7}$ Kelvin Falcão Klein, "W. G. Sebald e o olho da História”, 2017, p. 108-120.

${ }^{8}$ Idem, "W. G. Sebald: pós-memória, palavra e imagem", 2017, p. 209-224.

${ }^{9}$ Idem, "Atenção flutuante e deriva em W. G. Sebald", 2016, p. 127-141.
} 
permanente de utilizar as imagens não como ilustração do texto, em uma operação linear de acréscimo de sentido, e sim todo o contrário: as imagens funcionam como manobras de deslizamento dos sentidos possíveis do texto, e uma das manobras exercitadas por Sebald diz respeito justamente à relação entre reino dos mortos e espetáculo midiático, para usar os termos de Kittler. Em outras palavras, ao construir suas ficções a partir do confronto entre texto e imagem (na tensão entre dois registros midiáticos antagônicos), Sebald oscila entre o registro alucinatório (que marca a literatura de autores como Balzac, Poe e Keller) e o registro técnico-midiático (hegemônico no século XX a partir de Walter Benjamin).

Em Austerlitz, seu último romance, Sebald posiciona estrategicamente uma referência à novela de Balzac, $O$ coronel Chabert, publicada em 1832 e, em sua forma definitiva depois de ajustes, em 1844. A disposição da novela de Balzac no interior da trama de Sebald funciona como uma espécie de dispositivo que permite o retorno de fantasmas e espectros do passado. Com isso, Sebald oferece um comentário sobre Balzac (e o regime alucinatório de reivindicação das imagens no qual ele está imerso) que também é um uso do texto, uma performance e uma atualização a partir de um texto do passado (que passa a fazer parte da dinâmica de um texto do presente, exemplificando dessa forma a ideia sebaldiana, defendida em diferentes facetas ao longo de Austerlitz, de que passado e presente estão em diálogo, em relação constante).

O romance conta a história de como Daffyd Elias se torna Jacques Austerlitz - ou ainda, de como Austerlitz retoma e resgata seu nome de batismo e, com isso, sua história recalcada (em 1939, ainda criança, ele é enviado para o País de Gales para escapar dos nazistas, e recebe o nome Daffyd Elias). Adiante na história, Austerlitz vai a Praga e reencontra Vera, amiga da família, responsável pela revelação de memórias que o protagonista não tem como acessar. Vera entrega a Austerlitz “duas fotografias de formato pequeno", encontradas "por acaso em um dos cinquenta e cinco volumes carmesins de Balzac que lhe fora parar nas mãos"; ela encontra as fotografias "folheando as páginas da famosa história da grande injustiça sofrida pelo coronel Chabert”, mas “como as duas fotos tinham ido parar entre as páginas era um mistério para 
ela"; esses artefatos têm "uma natureza insondável”, "própria de tais fotografias emersas do esquecimento": a impressão é "que alguma coisa se agita dentro delas, como se ouvíssemos pequenos gemidos de desespero", como se "as fotos tivessem memória própria e se lembrassem de nós, de como nós, os sobreviventes, e aqueles que já não estão entre nós, éramos então"10.

A novela de Balzac é tanto um adereço cênico - que ocupa determinado espaço na trama, contribuindo para oferecer informações que até aquele momento não se tinha - quanto um cristal complexo de condensação de temporalidades e ideias (o coronel morto e a infância soterrada de Austerlitz que retornam). Em Balzac, Chabert é essa entidade do passado que tem memória própria e que lembra de como eram os sobreviventes e os não sobreviventes, especialmente Napoleão; em Sebald, essa potência da entidade que vem do passado é tornada difusa e canalizada para um comentário sobre a aura ambígua da fotografia - uma dimensão difusa, contudo, que é tornada palpável e contundente com o recurso ao livro como artefato e objeto, encontrado por acaso (Sebald encena o confronto das mídias apontado por Kittler: de um lado, a mídia livro e seu apelo ao alucinatório; de outro, a mídia fotografia e seu apelo à divisão técnica dos sentidos).

Não é por acidente, contudo, que Sebald escolhe $O$ coronel Chabert como recurso intertextual. O coronel Chabert de Balzac, morto-vivo que sobrevive soterrado pelos cadáveres de seus companheiros, diz que irá à praça Vendôme, "até o pé da coluna da praça Vendôme", gritar seu nome e seus feitos e que, diante disso, “o bronze me reconhecerá!”"11. Balzac, sutil e rapidamente, conjuga dois destinos, duas fábulas da vida póstuma: um coronel que retorna como mendigo, os mais de mil canhões de russos e austríacos da Batalha de Austerlitz transformados na Colonne Vendôme (é fundamental reparar no retorno deste significante: Austerlitz). A coluna foi construída em 1810 para comemorar uma das batalhas vencidas por Napoleão (e pelo coronel Chabert, e por tantos outros), a Batalha dos Três Imperadores, em 2 de dezembro de 1805. A Colonne Vendôme, contudo, é também resgate e retomada da Coluna de

${ }^{10}$ Winfried Georg Sebald, Austerlitz, 2008, p. 178-180.

${ }^{11}$ Honoré de Balzac, O coronel Chabert, 2012, p. 46. 
Trajano, construída em Roma de 107 a 113 para comemorar os feitos do Imperador Trajano, especialmente a vitória sobre os Dácios. A primeira estátua de Napoleão posta no alto da coluna, em 1810 (que foi retirada em 1814 e derretida em 1818), retratava o intrépido corso vestido à romana, à maneira dos Césares. Essa primeira estátua (Napoleão-Trajano) foi derretida em 1818, e seu material destinado à construção da estátua de Henrique IV, Henri le Grand, rei da França de 1589 a 1610. A primeira estátua de Henrique IV foi inaugurada em 1614, tendo sido destruída durante a Revolução Francesa. Com a queda de Napoleão e o advento da Restauração da Monarquia, uma segunda estátua de Henrique IV é feita em 1814 (ironicamente, o cavalo utilizado como modelo para essa estátua foi retirado por Napoleão do Portão de Bramdenburgo, em Berlim - eram quatro cavalos de bronze, e foram todos enviados a Paris em 1806). A terceira estátua, que ainda está lá, foi feita em 1818 com o bronze do NapoleãoTrajano derretido.

É do interior de um livro de Balzac que emerge, na narrativa do romance Austerlitz, o registro de um mundo perdido, recalcado e soterrado - as duas fotografias, uma delas mostrando o menino Jacques Austerlitz fantasiado (imagem famosíssima, reproduzida em várias edições de Austerlitz, inclusive a brasileira), e outra mostrando a encenação de um espetáculo, com dois atores no canto esquerdo e uma ampla paisagem alpina de pano de fundo. A fotografia da encenação teatral, por exemplo, não serve de ilustração à trama, e sim como comentário visual ao denso processo de evocação, rememoração e reconfiguração do passado vivenciado por Austerlitz. O fato de as fotografias estarem dentro de um livro de Balzac reforça a hipótese postulada acima, a partir de Kittler, de que Sebald está mesclando paradigmas midiáticos conflitivos, mostrando que o discurso romanesco não está ancorado necessariamente (e essencialmente) em um dos modelos, podendo ser alucinatório e técnico-midiático ao mesmo tempo. Com o posicionamento da novela de Balzac no centro do romance, Sebald não acrescenta camadas de sentido apenas à trajetória específica do protagonista, mas acrescenta também outra complexa engrenagem no sistema geral de referências de sua obra como um todo: Balzac funciona como metonímia de todo um mundo perdido 
(Chabert é um dos cinquenta e cinco volumes luxuosamente encadernados atrás de uma cristaleira), o mundo burguês organizado do século XIX, objeto de estudo não só de Jacques Austerlitz, mas também de Walter Benjamin, paisagem afetiva e efetiva de autores como Adalbert Stifter, Gottfried Keller e Eduard Mörike, leituras constantes de Sebald.

É possível, ainda, perceber que os dois livros (o de Sebald, Austerlitz, e o de Balzac, O coronel Chabert) levam como título o nome do protagonista - e que, além disso, são dois protagonistas envolvidos na tarefa de resgatar da morte (do esquecimento, do soterramento, do recalque) uma vida vivida outrora, ligada a um registro de experiência já indisponível no presente ao qual estão ligados (a infância de Austerlitz e a glória napoleônica de Chabert, respectivamente). Pelo viés napoleônico, Chabert é a oportunidade que tem Sebald de reforçar as ligações subterrâneas com o capítulo de Vertigem - a primeira obra de prosa publicada por ele - dedicado a Stendhal, o romancista napoleônico por excelência do século XIX (algo que é reforçado também dentro da dinâmica específica de Austerlitz, pois é possível lembrar que o professor favorito do protagonista - André Hilary - é um dedicado estudioso das campanhas napoleônicas). Esses dois pontos napoleônicos da obra de Sebald (Balzac/Chabert em Austerlitz, Stendhal em Vertigem) vão convergir no futuro, na obra inacabada dedicada à Córsega, Campo Santo, na qual o narrador visita a Casa Bonaparte e comenta o daltonismo do Imperador, que o impedia de diferenciar vermelho e verde - quanto mais sangue derramava, mais frescos via os gramados.

Em linhas gerais, é possível dizer que Sebald incorpora ao romance a inscrição de um paradigma midiático perdido, algo que é realizado não apenas com a menção a Balzac e ao Coronel Chabert, mas também com a disposição material das duas fotografias (o menino e a encenação teatral) no corpo do texto. "Literatura como arte da palavra, teatro como teatro, filme como fílmico e rádio como radiofônico", escreve Kittler em Gramofone, Filme, Typewriter, "todos esses lemas da década de 1920 eram linhas de defesa contra os sistemas de mídias conectadas que estavam se aproximando"; seguindo o modelo de Mallarmé, "o fílmico e o radiofônico" deveriam "portar a arte pela arte também 
nos campos óptico e acústico" e, no campo do literário, "desde 28 de dezembro de 1895, quando os irmãos Lumière apresentaram seu projetor de cinema, a impossibilidade de ser filmada era o critério distintivo inconfundível da literatura" ${ }^{2}$. A aura melancólica da ficção de Sebald decorre, em parte, desse envio em direção a paradigmas midiáticos do passado, tornados presentes na narrativa não apenas com a reprodução das imagens, mas também com o permanente esforço dos personagens de evocar o passado a partir de fragmentos da memória. Sebald desnaturaliza nossa própria contemporaneidade ao apresentar, em suas ficções, o processo de estratificação histórica que tornou possível a conexão desses sistemas de mídias de que fala Kittler. O ressurgimento das fotografias vindas do interior de um livro de Balzac são revelações tanto do passado do protagonista quanto do passado da técnica e das mídias (confrontadas continuamente com o literário, tanto na reconstrução imaginativa de Sebald, quanto na elaboração teórica de Kittler).

John Sears argumenta que, em Austerlitz, as duas fotografias operam em conjunto, o cenário teatral funcionando como pano de fundo simbólico para a emergência da foto do menino, possibilitando ao protagonista a ocasião de reconstrução do passado. ${ }^{13}$ Avi Kempinski, por sua vez, argumenta que a inscrição no verso da fotografia contribui para sua ancoragem no passado e para sua autenticidade, ao mesmo tempo que salienta a não materialidade (a inexistência e, portanto, a incompletude da busca de Austerlitz por suas origens) da tão buscada imagem da mãe. ${ }^{14}$ Ao argumentar que a fotografia do menino por si só não disparou a memória (pois o protagonista não reconhece a si próprio na imagem), Mary Griffin Wilson ressalta que seu efeito depende da revelação de Vera de que aquele é, de fato, Austerlitz, inscrevendo sua presença no texto, a presença de uma criança que não está morta ou perdida, e sim à espera de algo que possa transformar seu status. ${ }^{15}$ Frances L. Restuccia salienta como a

\footnotetext{
${ }^{12}$ Friedrich Kittler, Gramofone, filme, typewriter, 2019, p. 244-245.

${ }^{13}$ John Sears, "Photographs, Images, and the Space of Literature in Sebald's Prose", 2007, p. 223.

${ }^{14}$ Avi Kempinski, “'Quel Roman!': Sebald, Barthes, and the Pursuit of the Mother-Image”, 2007, p. 467-469.

${ }^{15}$ Mary Griffin Wilson, "Sheets of Past: Reading the Image in W. G. Sebald's Austerlitz", 2013, p. 58.
} 
fotografia do menino enfatiza a dimensão melancólica do resgate de Austerlitz, apontando simultaneamente para uma falta e para um movimento diante de um estado psíquico congelado (mas permanece a questão, na visão de Restuccia, de saber se ele se beneficia desse encontro com o eu do menino que não superou ou se seu gozo melancólico é reforçado pela intensidade da experiência). ${ }^{16}$

Em entrevista concedida a Christian Scholz em 14 de novembro de 1997 parcialmente transmitida por rádio, depois parcialmente transcrita e publicada, em 2000, no Neuer Zürcher Zeitung, e agora disponível no volume coletivo Searching for Sebald -, Sebald dá detalhes a respeito da fotografia que acompanha a imagem de Austerlitz-menino, ou seja, a imagem do casal com roupas de inverno sobre um palco teatral (reproduzida na página 179 da edição brasileira de Austerlitz). Sebald diz que encontrou, muitos anos antes (não é específico com relação à data ou ao local de aquisição, infelizmente), uma fotografia do tamanho carta (21 x $27 \mathrm{~cm}$ ), mostrando duas pessoas em um palco diante de uma paisagem alpina pintada, com glaciares e florestas aparecendo. Sebald ainda diz que essa é uma das imagens em que pensa com frequência, que de certa forma o assombra e que ele gostaria de fazer algo com essa fotografia (nessa época, Austerlitz já era um projeto em andamento - iniciado em algum ponto de 1996, depois de Sebald abandonar seu projeto sobre a Córsega, do qual fragmentos foram publicados no volume póstumo Campo Santo). ${ }^{17}$ Além disso, nessa entrevista, Sebald é bastante eloquente quanto à relação entre reino dos mortos e espetáculo midiático, antecipando uma série de reflexões que encontraremos em Austerlitz. Ele diz a Scholz que pensa nas fotografias em preto e branco - ou antes nas zonas cinzentas que se encontram em fotografias desse tipo - como territórios localizados entre a morte e a vida: Sebald remete à imaginação arcaica defensora da ideia de que há um gradativo terreno que liga mortos e vivos, dentro do qual as pessoas estão em permanente deslocamento, como uma espécie de deserto ou purgatório. ${ }^{18} \mathrm{Em}$ determinado ponto do romance, Austerlitz diz ao narrador: "sinto cada vez mais como se o tempo não

${ }^{16}$ Frances L. Restuccia, "Sebald's punctum awakening to holocaust trauma in Austerlitz", 2005, p. 313 .

${ }^{17}$ Christian Scholz, "But the Written Word Is Not a True Document': A Conversation with W. G. Sebald on Literature and Photography", 2007, p. 109.

${ }^{18}$ Ibidem, p. 108. 
existisse em absoluto, somente diversos espaços que se imbricam segundo uma estereometria superior, entre os quais os vivos e os mortos podem ir de lá para cá como bem quiserem"19.

A foto de Austerlitz-menino, por sua vez, é retirada de um cartão-postal fabricado no início do século XX, comprado por Sebald na Inglaterra, muito provavelmente em um antiquário. Douglas Pompeu, que analisou o espólio de Sebald conservado em Marbach (DLA, Deutschen Literaturarchivs), reproduz o verso do cartão-postal em sua dissertação, indicando que é possível ler o endereço do estúdio fotográfico: Photo by Allen Nield's Successors, 68 Wellington Rd. South, Stockport. Além disso, é possível discernir claramente uma breve mensagem escrita à mão: Jackie Grindrod / Train bearer to the Rose Queen. O estúdio Nield's Successors funcionou, em Stockport, de 1923 a 1938. Como a maioria dos cartões até o fim do século XIX não tinham o verso dividido (não era permitido escrever no verso, espaço destinado às autoridades postais), as mensagens eram escritas diretamente sobre a fotografia, sem invadir o espaço destinado à inscrição do endereço do destinatário. O cartão-postal comprado por Sebald, de acordo tanto com a divisão já encontrada no verso quanto com o período de atuação do estúdio, pode ser datado aproximadamente do período entreguerras. ${ }^{20}$

Pompeu ainda ressalta como o cartão-postal como objeto - a inscrição no verso, as regras de composição da fotografia, os trajes, a pose - remonta aos primórdios do retrato fotográfico e sua popularização. Nessas primeiras décadas do século XX, as fotografias feitas ao ar livre (para aproveitar a luminosidade) geralmente previam poses e adereços, sobretudo se havia a intenção de transformá-las em cartões-postais para envio a familiares. O processo era demorado, envolvendo longo tempo de exposição para a fotografia ser bemsucedida, o que por vezes gerava poses ou torções faciais que hoje nos parecem pitorescas, ao mesmo tempo que registrava, na dimensão corporal dos modelos, a variação técnica do meio e sua indissociável ligação com a paisagem

${ }^{19}$ W. G. Sebald, Austerlitz, 2008, p. 182.

${ }^{20}$ Douglas Valeriano Pompeu, As sombras do real em Austerlitz: investigação sobre a fotografia em WG Sebald, 2012, p. 153. 
imaginativa de uma época. Pompeu ainda aproxima a imagem de Austerlitzmenino daquela de Franz Kafka (com mais ou menos seis anos, em uma espécie de jardim de inverno, vestindo roupas rendadas, apertadas, segurando um chapéu de grandes abas), comentada por Walter Benjamin em sua "Pequena história da fotografia” ${ }^{21}$ (ensaio que Sebald conhecia e que contribuiu para sua relação intertextual com a obra e a figura de Kafka, como argumenta Markus Zisselsberger). ${ }^{22}$

Em seu livro W. G. Sebald: Leben und literarisches Werk, de 2020, Uwe Schütte também menciona a especificidade do cartão-postal como objeto, transcrevendo tanto a escrita à mão referente ao nome Jackie Grindrod (que se presume ser a primeira inscrição, na ocasião do envio do cartão-postal possivelmente em algum momento da década de 1930) quanto a escrita referente à localidade e ao preço, Stockport 3op (que se presume ser uma segunda inscrição, feita provavelmente pela pessoa que estava vendendo e de quem Sebald talvez tenha adquirido o cartão-postal - 3op seriam 30 pence). Schütte ainda aponta uma contradição no texto, explicada pelo fato de Sebald querer incorporar ao romance a escrita exata do verso do cartão-postal ("Train bearer to the Rose Queen"23, "pajem da Rainha das Rosas" na edição brasileira). A inscrição diz respeito a uma procissão à luz do dia, e não ao baile noturno de máscaras de que fala Vera a Austerlitz no romance. Essas procissões, segundo Schütte, remontam aos costumes pagãos da primavera e configuram uma tradição específica e há muito desaparecida no noroeste da Inglaterra, o que reforça a explicação da inscrição Stockport no verso, que se refere a um local na Grande Manchester (onde Sebald morou de 1966 a 1969). ${ }^{24}$ É possível, ainda, mencionar que James Wood, em artigo de 2011 dedicado a Austerlitz (hoje incluído em seu livro The Fun Stuff and Other Essays), fala de sua visita ao arquivo em Marbach e sua descoberta do cartão-postal do pajem - Wood

${ }^{21}$ Ibidem, p. 154.

${ }^{22}$ Markus Zisselsberger, "Melancholy Longings: Sebald, Benjamin and the Image of Kafka", 2007, p. 289-291.

${ }^{23}$ Winfried Georg Sebald, Austerlitz, 2008, p. 182.

${ }^{24}$ Uwe Schütte, W. G. Sebald: Leben und literarisches Werk, 2020, p. 441. 
enfatiza justamente a inscrição Stockport 3op, afirmando que se trata de um cartão-postal “comum”"

Com o auxílio do arquivo de Sebald, portanto, é possível rastrear uma série de movimentações discursivas que precedem o posicionamento das imagens no interior de Austerlitz. No caso das duas imagens analisadas aqui - o casal sobre o palco e o menino vestido de pajem -, elas parecem cobrir um terreno que é tanto retrospectivo quanto prospectivo: a imagem do casal é mencionada por Sebald antes da publicação de Austerlitz, enfatizando com isso o longo trabalho prévio de reflexão, por parte do autor, das possíveis posições (e ressonâncias simbólicas) dessa fotografia específica na trama; a imagem do menino, por sua vez, foi singularizada tanto pelo trabalho editorial (ao ser posicionada na capa do romance em várias edições) quanto pelo trabalho crítico, que a transformou em uma espécie de metonímia da poética de Sebald como um todo. Minha intenção aqui foi de salientar como essas duas imagens estão dentro da história, fazendo parte da dinâmica própria da trama, manipuladas pelos personagens no decorrer do romance (não são inserções elusivas feitas por Sebald, essa entidade suprarromanesca que organiza o fluxo da narrativa e monta as imagens no texto).

Por fim, gostaria de salientar a complexidade da cena montada por Sebald, o que redunda em uma espécie de proliferação discursiva por parte da crítica que busca esmiuçar suas várias camadas. A emergência das duas fotografias resgata Balzac como elemento de intertextualidade, articulando o romance Austerlitz com a tradição realista do século XIX; ao mesmo tempo, resgata a memória possível do passado do personagem, ressaltando que se trata de uma reconstrução hipotética baseada na interferência desses dois artefatos (as duas fotografias). A partir disso, o personagem Jacques Austerlitz mobiliza o arquivo e a materialidade de sua própria busca como autor e indivíduo, acumulando material que mais tarde será legado ao narrador e, finalmente, aos leitores. Por fim, Sebald ainda mobiliza distintos registros midiáticos com a evocação do volume de Balzac e a justaposição das duas imagens, postulando e complexificando a articulação proposta por Kittler entre reino dos mortos e 25 “ordinary”. James Wood, The Fun Stuff and Other Essays, 2012, p. 25. Tradução minha. 
espetáculo midiático. De resto, Sebald desenvolve aquela forma periscópica de narrativa que, na entrevista com Michael Silverblatt, afirma ter apreendido de Thomas Bernhard. ${ }^{26}$ Ou seja, o contato muito específico e localizado entre duas imagens (que dialogam entre si e, sobretudo, com a narrativa escrita do romance) traz a questão técnica, teórica e conceitual da relação possível entre paradigmas midiáticos, a questão filosófica e metafísica da relação entre vida e morte, bem como a questão historiográfica sobre as relações possíveis entre passado e presente, registro dos fatos e das vidas, literatura, linguagem e ficção.

\section{Referências}

ANDRIOPOULOS, Stefan. Aparições espectrais: o idealismo alemão, o romance gótico e a mídia óptica. Tradução de Vera Ribeiro. Rio de Janeiro: Contraponto, 2014.

ANDRIOPOULOS, Stefan. Possuídos: crimes hipnóticos, ficção corporativa e a invenção do cinema. Tradução de Vera Ribeiro. Rio de Janeiro: Contraponto, 2014.

BALZAC, Honoré de. O coronel Chabert. Tradução de Eduardo Brandão. São Paulo: Companhia das Letras, 2012.

KEMPINSKI, Avi. "Quel Roman!": Sebald, Barthes, and the Pursuit of the Mother-Image. In: PATT, Lise (ed.). Searching for Sebald. Photography after W. G. Sebald. Los Angeles: The Institute of Cultural Inquiry, 2007, p. 456-471.

KITTLER, Friedrich. Gramofone, filme, typewriter. Tradução de Daniel Martineschen e Guilherme Gontijo Flores. Belo Horizonte; Rio de Janeiro: Editoras da UFMG e UERJ, 2019.

KITTLER, Friedrich. Mídias ópticas. Tradução de Markus Hediger, Rio de Janeiro: Contraponto, 2016.

KLEIN, Kelvin Falcão. W. G. Sebald e o olho da História. Cadernos Benjaminianos - Revista do Núcleo Walter Benjamin, Faculdade de Letras da Universidade Federal de Minas Gerais, v. 12, n. 1, p. 108-120, fev. 2017.

KLEIN, Kelvin Falcão. W. G. Sebald: pós-memória, palavra e imagem. Aletria: Revista de Estudos de Literatura - Programa de Pós-Graduação em Estudos Literários, UFMG, v. 27, n. 2, p. 209-224, 2017.

${ }^{26}$ Michael Silverblatt, “A Poem of an Invisible Subject (Bookworm interview)”, 2007, p. 83. 
KLEIN, Kelvin Falcão. Atenção flutuante e deriva em W. G. Sebald. Revista Maracanan - Programa de Pós-graduação em História, UERJ, v. 12, n. 14, p. 127-141, jan. 2016.

POMPEU, Douglas Valeriano. As sombras do real em Austerlitz: investigação sobre a fotografia em WG Sebald. 2012. 201f. Dissertação (Mestrado em Letras) - Faculdade de Filosofia, Letras e Ciências Humanas, Universidade de São Paulo, São Paulo, SP.

RESTUCCIA, Frances L. Sebald's punctum awakening to holocaust trauma in Austerlitz. European Journal of English Studies, v. 9, n. 3, p. 301-322, Dezembro 2005.

SCHOLZ, Christian. "But the Written Word Is Not a True Document": A Conversation with W. G. Sebald on Literature and Photography. In: PATT, Lise (ed.). Searching for Sebald: Photography after W. G. Sebald. Los Angeles: The Institute of Cultural Inquiry, 2007, p. 104-109.

SCHÜTTE, Uwe. W. G. Sebald: Leben und literarisches Werk. Berlim: De Gruyter, 2020.

SEARS, John. Photographs, Images, and the Space of Literature in Sebald's Prose. In: PATT, Lise (ed.). Searching for Sebald. Photography after W. G. Sebald. Los Angeles: The Institute of Cultural Inquiry, 2007, p. 204-225.

SEBALD, Winfried Georg. Austerlitz. Tradução de José Marcos Macedo. São Paulo: Companhia das Letras, 2008.

SILVERBLATT, Michael. A Poem of an Invisible Subject (Bookworm interview). In: SCHWARTZ, Lynne Sharon (ed.). The Emergence of Memory: conversations with W. G. Sebald. Nova York: Seven Stories Press, 2007.

WILSON, Mary Griffin. Sheets of Past: Reading the Image in W. G. Sebald's Austerlitz. Contemporary Literature, University of Wisconsin Press, v. 54, n. 1, p. 49-76, Spring 2013.

WOOD, James. The Fun Stuff and Other Essays. Nova York: Farrar, Straus and Giroux, 2012.

ZISSELSBERGER, Markus. Melancholy Longings: Sebald, Benjamin, and the Image of Kafka. In: PATT, Lise (ed.). Searching for Sebald: Photography after W. G. Sebald. Los Angeles: The Institute of Cultural Inquiry, 2007, p. 280-301.

ISSELSBERGER, Markus. Melancholy Longings: Sebald, Benjamin and the Image of Kafka. In: PATT, Lise (ed.). Searching for Sebald. Photography after W. G. Sebald. Los Angeles: The Institute of Cultural Inquiry, 2007, p. 280-301. 
Referência para citação deste artigo

KLEIN, Kelvin Falcão. W. G. Sebald: reino dos mortos e espetáculo midiático. Revista PHILIA | Filosofia, Literatura \& Arte, Porto Alegre, volume 3, número 2, p. 83 - 100, dezembro de 2021. 